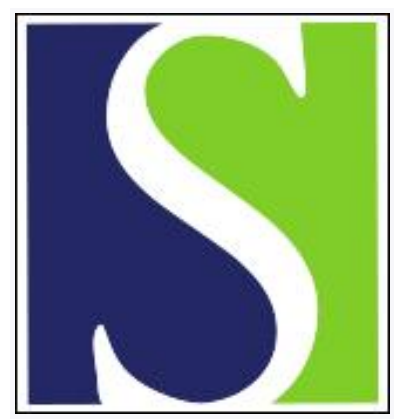

Scand J Work Environ Health 2021;47(2):163-168

https://doi.org/10.5271/sjweh.3926

Published online: 19 Oct 2020, Issue date: 01 Mar 2021

Dust exposure and the impact on hospital readmission of farming and wood industry workers for asthma and chronic obstructive pulmonary disease (COPD)

by Vested A, Kolstad HA, Basinas I, Burdorf A, Elholm G, Heederik D, Jacobsen GH, Kromhout $H$, Omland $\varnothing$, Schaumburg I, Sigsgaard T, Vestergaard JM, Wouters IM, Schlünssen V

Among individuals with asthma there was an increased risk of asthma hospital readmission with higher recent organic dust exposure most pronounced for individuals with a maximum of two years of exposure in the follow-up period. For COPD, a decreased risk was observed

Affiliation: Department of Occupational Medicine, Danish Ramazzini Centre, Aarhus University Hospital, Aarhus, Denmark. anneveed@rm.dk

Key terms: air pollutant; asthma; chronic obstructive pulmonary disease; COPD; dust exposure; exposure; farmer; farming; hospital readmission; industry exposure matrix; lung disease; wood industry; woodworker

This article in PubMed: www.ncbi.nlm.nih.gov/pubmed/33073852 


\title{
Dust exposure and the impact on hospital readmission of farming and wood industry workers for asthma and chronic obstructive pulmonary disease (COPD)
}

\author{
by Anne Vested, PhD, ${ }^{1,2}$ Henrik A Kolstad, PhD, ${ }^{1}$ loannis Basinas, PhD, ${ }^{2,3}$ Alex Burdorf, PhD, ${ }^{4}$ Grethe Elholm, PhD, ${ }^{2}$ Dick \\ Heederik, PhD, ${ }^{5}$ Gitte H Jacobsen, PhD, ${ }^{6}$ Hans Kromhout, PhD, ${ }^{5}$ Øyvind Omland, PhD, ${ }^{7}$ Inger Schaumburg, PhD, ${ }^{2}$ Torben \\ Sigsgaard, PhD, ${ }^{2}$ Jesper M Vestergaard, Master of IT, Software Development, ${ }^{1,6}$ Inge M Wouters, PhD, ${ }^{5}$ Vivi Schlünssen, PhD 2,8
}

\begin{abstract}
Vested A, Kolstad HA, Basinas I, Burdorf A, Elholm G, HeederikD, Jacobsen GH, Kromhout H, Omland Ø, Schaumburg I, Sigsgaard T, Vestergaard JM, Wouters IM, Schlünssen V. Dust exposure and the impact on hospital readmission of farming and wood industry workers for asthma and chronic obstructive pulmonary disease (COPD). Scand J Work Environ Health. 2021;47(2):163-167. doi:10.5271/sjweh.3926
\end{abstract}

Objectives It is still not well established how occupational air pollutants affect the prognosis of asthma or chronic obstructive pulmonary disease (COPD). This study uses nationwide Danish registers and quantitative dust industry exposure matrices (IEM) for the farming and wood industries to estimate whether previous year dust exposure level impacts hospital readmissions for workers diagnosed with asthma or COPD.

Methods We identified all individuals with a first diagnosis of either asthma (769 individuals) or COPD (342 individuals) between 1997 and 2007 and followed them until the next hospital admission for asthma or COPD, emigration, death or 31 December 2007. We included only individuals who worked in either the wood or farming industries at least one year during follow-up. We used logistic regression analysis to investigate associations between dust exposure level in the previous year and hospital readmission, adjusting for sex, age, time since first diagnosis, socioeconomic status, and labor force participation.

Results Asthma readmissions for individuals with low and high dust exposure were increased [adjusted rate ratio $\left(R_{\mathrm{adj}}\right)$ 2.52, 95\% confidence interval (CI) 1.45-4.40] and $\mathrm{RR}_{\mathrm{adj}} 2.64$ (95\% CI 1.52-4.60), respectively. For COPD readmission, the risk estimates were $\mathrm{RR}_{\mathrm{adj}} 1.36(95 \% \mathrm{CI} 0.57-3.23)$ for low and $\mathrm{RR}_{\mathrm{adj}} 1.20(95 \% \mathrm{CI}$ 0.49-2.95) for high exposure level in the previous year. For asthma readmission, stratified analyses by type of dust exposure during follow-up showed increased risks for both wood dust $\left[\mathrm{RR}_{\text {adj }} 2.67\right.$ (95\% CI 1.35-5.26) high exposure level] and farming dust [RR $\mathrm{RR}_{\mathrm{adj}} 3.59$ (95\% CI 1.11-11.59) high exposure level]. No clear associations were seen for COPD readmissions.

Conclusions This study indicates that exposure to wood or farm dust in the previous year increases the risk of hospital readmission for individuals with asthma but not for those with COPD.

Key terms air pollutant; farmer; industry exposure matrix; lung disease; woodworker.

Asthma and chronic obstructive lung disease (COPD) are prevalent obstructive lung diseases contributing substantially to morbidity and mortality worldwide (1). Organic dust exposure, most importantly from the farming and wood industries, is a suggested risk factor for both asthma and $\operatorname{COPD}(2,3)$. However, how organic dust exposure affects individuals with asthma or COPD is not well established. We hypothesize that recent exposure to wood or farming dust is a risk factor for rehospitalization among individuals with asthma or COPD. We investigated this hypothesis in a longitudinal study using nationwide Danish administrative health and industry registers and quantitative dust industry exposure matrices (IEM) where hospital readmissions for

1 Department of Occupational Medicine, Danish Ramazzini Centre, Aarhus University Hospital, Aarhus, Denmark.

2 Department of Public Health, Section for Environment, Occupation and Health, Danish Ramazzini Centre, Aarhus University, Aarhus, Denmark.

3 Centre for Human Exposure Science, Institute of Occupational Medicine, Edinburgh, United Kingdom.

4 Department of Public Health, Rotterdam, Erasmus Medical Center Rotterdam, The Netherlands.

5 Division of Environmental Epidemiology, Institute for Risk Assessment Sciences, Utrecht University, The Netherlands

6 Department of Occupational Medicine, Danish Ramazzini Centre, University Research Clinic, Regional Hospital West, Jutland, Denmark.

7 Department of Occupational Medicine, Danish Ramazzini Centre, Aalborg University Hospital, Aalborg, Denmark.

8 National Research Centre for the Working Environment, Copenhagen, Denmark.

Correspondence to: Anne Vested, Department of Occupational Medicine, Danish Ramazzini Centre, Aarhus University Hospital, Aarhus, Denmark. [E-mail: anneveed@rm.dk] 
asthma and COPD cases among ever farming and wood workers during follow-up were identified.

We aimed to investigate the association between previous year exposure to wood or farm dust and readmission for asthma or COPD.

\section{Methods}

We recently published a study on the association between farming and wood dust exposure and COPD incidence using a population of Danish workers who worked in the farming or wood industries 1964-2007 and were born 1933-1977 (4). Using this population, we identified all individuals with a first hospital diagnosis of either asthma or COPD between 1997-2007 in the Danish National Patient Register (4) who were blue-collar workers in either the wood or farming industries after their initial asthma or COPD diagnosis. Employment data came from the Supplementary Pension Fund register, which provides annual information on employment (industry code) according to the Danish Industrial Classification of Economic Activities. Overall, 769 workers diagnosed with asthma (3777 person-years) and 342 with COPD (1369 person-years) were included.

The population was followed from the year after their first asthma or COPD hospital diagnosis (including emergency room and department visits) until the year of first hospital readmission for asthma or COPD, respectively, with censoring for death, emigration, loss to follow-up, 65 years of age, retirement or end of follow-up on 31 December 2007.

COPD was defined according to the International Classification of Diseases, $10^{\text {th }}$ revision (ICD-10) as emphysema (J43, J43.0, J43.1, J43.2, J43.8, J43.9) or other chronic obstructive pulmonary disease (J44, J44.0, J44.1 J44.8, J44.9). Asthma was defined by ICD-10 codes for asthma (J45, J45.0, J45.1, J45.8, J45.9) or status asthmaticus (J46, J46.9).

We established wood and farming industry-specific time-dependent IEM for inhalable dust exposure levels as described earlier (4). Briefly, arithmetic mean exposure levels were estimated from the WOODEX exposure database (5) and personal measurements from Danish farmers (6) both based on the inhalable dust fraction. The wood industry IEM included quantitative dust estimates for six industries: (i) sawmilling/planing of wood, (ii) manufacture of veneer boards/wood-based boards, (iii) manufacture of builders carpentry/joinery, (iv) manufacture of wooden packaging, (v) furniture industry, and (vi) carpenter and joiner business/construction. The farming IEM included estimates for crop-, cattle-, pig-, poultry-, mixed-, and fur-animal farming.

Each person-year of employment within the wood or farming industries during follow-up was assigned an exposure level based on the IEM, and follow-up years were further divided into three exposure groups [no

Table 1. Baseline characteristics of 769 workers with an asthma diagnosis and 342 workers with a COPD diagnosis working in the Danish farming or wood industry during follow-up (1997-2007) by dust exposure intensity previous year.

\begin{tabular}{|c|c|c|c|c|c|c|c|c|}
\hline \multirow[t]{3}{*}{ Worker characteristics } & \multicolumn{4}{|c|}{$\begin{array}{l}\text { Asthma population } \\
\text { Dust exposure intensity previous year }\left(\mathrm{mg} / \mathrm{m}^{3}\right)\end{array}$} & \multicolumn{4}{|c|}{$\begin{array}{l}\text { COPD population } \\
\text { Dust exposure intensity previous year }\left(\mathrm{mg} / \mathrm{m}^{3}\right)\end{array}$} \\
\hline & 0 & $>0-0.70$ & $>0.70-5.70$ & Missing & 0 & $>0-0.70$ & $>0.70-5.70$ & Missing \\
\hline & $17 \%(N=131)$ & $39 \%(\mathrm{~N}=299)$ & $40 \%(N=306)$ & $4 \%(N=33)$ & $13 \%(\mathrm{~N}=46)$ & $41 \%(\mathrm{~N}=139)$ & $42 \%(N=143)$ & $4 \%(N=14)$ \\
\hline & $\%$ & $\%$ & $\%$ & $\%$ & $\%$ & $\%$ & $\%$ & \\
\hline \multicolumn{9}{|l|}{ Age group (years) } \\
\hline $20-39$ & 62 & 56 & 54 & & 33 & 15 & 15 & \\
\hline $40-49$ & 24 & 24 & 23 & & 26 & 30 & 19 & \\
\hline $50-69$ & 14 & 20 & 23 & & 41 & 55 & 66 & \\
\hline \multicolumn{9}{|l|}{ Sex } \\
\hline Male & 85 & 76 & 84 & & 89 & 76 & 89 & \\
\hline Female & 15 & 24 & 16 & & 11 & 24 & 11 & \\
\hline \multicolumn{9}{|l|}{ Labor force participation } \\
\hline Yes & 80 & 91 & 93 & & 63 & 83 & 93 & \\
\hline No & 20 & 9 & 7 & & 37 & 17 & 7 & \\
\hline \multicolumn{9}{|l|}{ Socioeconomic status } \\
\hline Top management & $<5^{a}$ & 0 & $<2^{a}$ & & 0 & 0 & 0 & \\
\hline Self-employed & 7 & 3 & $<2^{a}$ & & $<11^{a}$ & $<4^{a}$ & $<4^{\text {a }}$ & \\
\hline Higher and middle wage earners & $<5^{a}$ & 4 & $<2^{a}$ & & $<11^{a}$ & $<4^{a}$ & $<4^{a}$ & \\
\hline Employee at basic level & 70 & 85 & 88 & & 52 & 82 & 92 & \\
\hline Student/unemployed & 20 & 8 & 7 & & 37 & 13 & 5 & \\
\hline Missing & $<5^{a}$ & 0 & 0 & & $<11^{a}$ & 0 & $<4^{\text {a }}$ & \\
\hline \multicolumn{9}{|l|}{ Exposure source } \\
\hline Wood & $\sim 65$ & 76 & 56 & & $\sim 60$ & $\sim 80$ & $\sim 73$ & \\
\hline Farming & $\sim 35$ & 20 & 38 & & $\sim 40$ & $\sim 20$ & $\sim 27$ & \\
\hline Wood and farming & - & 4 & 6 & & - & - & - & \\
\hline
\end{tabular}


(reference), low $\left(>0-0.7 \mathrm{mg} / \mathrm{m}^{3}\right)$ and high $\left.\left(>0.7 \mathrm{mg} / \mathrm{m}^{3}\right)\right]$ according to the median exposure level. The majority of the reference group worked in other industries and a minority was unemployed (table 1).

Associations between previous year dust exposure and hospital readmission for asthma or COPD were investigated with logistic regression analyses with person-years as the unit of analysis providing rate ratios (RR). We additionally performed stratified analyses for farming and wood workers separately excluding those with mixed exposure. All independent variables were lagged one year. Age (10-year categories), sex, time since first diagnosis (in years), socioeconomic status (SES), and labor force participation (yes/no) were included as covariates. Labor force participation was defined as a period, minimally $25 \%$ of the year, with no public benefit payment. We performed all analyses using STATA 13.0 (Stata Corp, College Station, TX, USA) on Statistics Denmark.

\section{Results}

The study population spent $51 \%$ (asthma cases) and 57\% (COPD cases), respectively, of their follow-up time in wood or farming related industries. The mean number of follow-up years was 3.9 (range 1-10) for asthma patients and 3.4 (range 1-10) for COPD patients. At baseline, the mean age was 39 [standard deviation (SD) $10]$ and 49 (SD 9) years for asthma and COPD patients, respectively. Most were men, had a basic level work, and a stable labor force participation. The majority of the follow-up years were in the high dust exposure groups. Workers who were not exposed at the start of follow-up were more likely to have a lower degree of labor force participation and basic level work (table 1).

In the main analysis, asthma readmissions were associated with previous year dust exposure, adjusted rate ratios $\left(\mathrm{RR}_{\mathrm{adj}}\right) 2.52[95 \%$ confidence interval $(\mathrm{CI})$ 1.45-4.40] for low and $\mathrm{RR}_{\text {adj }} 2.64$ (95\% CI 1.52-4.60) for high exposure level compared to no exposure in the previous year (table 2). $\mathrm{RR}_{\mathrm{adj}}$ for COPD readmission were 1.36 (95\% CI $0.57-3.23)$ for low and 1.20 (95\% CI 0.49-2.95) for high exposure level in the previous year, compared to non-exposed in the previous year. For asthma readmissions, analyses stratified by type of dust exposure provided similar estimates as the main analysis for wood dust: $\mathrm{RR}_{\text {adj }} 2.38$ (95\% CI 1.23-4.60) and 2.67 (95\% CI 1.35-5.26) for low and high exposure level previous year, respectively. For those exposed to farming dust only, the $\mathrm{RR}_{\mathrm{adj}}$ were even higher: 4.03 (95\% CI 1.20-13.52) and 3.59 (95\% CI 1.11-11.59) (table 2). No clear association was seen for COPD readmissions, either for wood or farming dust. The small percentage
( $1.5 \%$ and $4 \%$, respectively) of the asthma and COPD populations exposed to both wood and farming dust during follow-up were excluded in the stratified analysis.

\section{Discussion}

In this analysis, being exposed to wood and farming dust in the previous year more than doubled the risk of hospital readmission for asthma patients but not COPD patients. Analyses stratified by wood and farming dust exposure showed even higher risk estimates for farmingdust-exposed workers.

Studies suggest that hospital readmissions for asthma and COPD are related to the level of ambient air pollution (7). However, we are not aware of studies investigating how occupational dust exposure impacts hospital readmissions for workers with asthma or COPD. A $40 \%$ increased risk of COPD (but not asthma) exacerbations has previously been reported among COPD patients living within a radius of $500 \mathrm{~m}$ of a livestock farm (8). People with asthma more often report uncontrolled

Table 2. Rate ratios (RR) of asthma ( $N=769,3777$ person-years) and COPD ( $N=342,1369$ person-years) readmissions. Overall results and results stratified by farming or wood dust. In order to comply with the General Data Protection Regulation, cases and numbers of personyears for the stratified analyses of the COPD cases cannot be stated in the table.

\begin{tabular}{|c|c|c|c|c|}
\hline $\begin{array}{l}\text { Exposure } \\
\text { level, }\left(\mathrm{mg} / \mathrm{m}^{3}\right)\end{array}$ & Cases & $\begin{array}{l}\text { Person- } \\
\text { years }\end{array}$ & $\mathrm{RR}_{\text {crude }}(95 \% \mathrm{Cl})$ & $\mathrm{RR}_{\mathrm{adj}}{ }^{\mathrm{a}}(95 \% \mathrm{Cl})$ \\
\hline \multicolumn{5}{|l|}{ Overall } \\
\hline \multicolumn{5}{|l|}{ Asthma } \\
\hline 0 & 24 & 1863 & 1 & 1 \\
\hline$>0-0.7$ & 45 & 932 & $3.89(2.35-6.42)$ & $2.52(1.45-4.40)$ \\
\hline$>0.7$ & 49 & 982 & $4.02(2.45-6.60)$ & $2.64(1.52-4.60)$ \\
\hline \multicolumn{5}{|l|}{ COPD } \\
\hline 0 & 13 & 568 & 1 & 1 \\
\hline$>0-0.7$ & 17 & 375 & $2.03(0.97-4.22)$ & $1.36(0.57-3.23)$ \\
\hline$>0.7$ & 17 & 426 & $1.77(0.85-3.69)$ & $1.20(0.49-2.95)$ \\
\hline \multicolumn{5}{|l|}{ Wood } \\
\hline \multicolumn{5}{|l|}{ Asthma } \\
\hline 0 & 18 & 1018 & 1 & 1 \\
\hline$>0-0.7$ & 34 & 697 & $2.85(1.60-5.09)$ & $2.38(1.23-4.60)$ \\
\hline$>0.7$ & 33 & 650 & $2.97(1.66-5.32)$ & $2.67(1.35-5.26)$ \\
\hline \multicolumn{5}{|l|}{ COPD } \\
\hline 0 & & & 1 & 1 \\
\hline$>0-0.7$ & & & $2.13(0.92-4.94)$ & $1.49(0.52-4.28)$ \\
\hline$>0.7$ & & & $1.42(0.59-3.41)$ & $0.90(0.30-2.75)$ \\
\hline \multicolumn{5}{|l|}{ Farming } \\
\hline \multicolumn{5}{|l|}{ Asthma } \\
\hline 0 & 5 & 762 & 1 & 1 \\
\hline$>0-0.7$ & 9 & 164 & $8.79(2.91-26.59)$ & $4.03(1.20-13.52)$ \\
\hline$>0.7$ & 14 & 273 & $8.18(2.92-22.94)$ & $3.59(1.11-11.59)$ \\
\hline \multicolumn{5}{|l|}{ COPD } \\
\hline 0 & & & 1 & 1 \\
\hline$>0-0.7$ & & & $1.34(0.24-7.45)$ & $1.32(0.19-9.08)$ \\
\hline$>0.7$ & & & $3.03(0.79-11.56)$ & $2.61(0.54-12.49)$ \\
\hline
\end{tabular}

${ }^{a}$ Adjusted for sex, age, years since first diagnosis, socioeconomic status, and labor force participation. 
asthma in jobs with airborne exposures compared to jobs without (9), and ongoing occupational exposure has been associated with a poorer prognosis for individuals with asthma caused by occupational agents (10). Barely any knowledge on the impact of occupational exposures on COPD prognosis is available. However, a study from the US suggests a history of occupational exposures to be associated with a worse prognosis in patients with COPD (11).

In the current study, we focused on the impact of previous year exposure to wood or farming dust on hospital readmissions for asthma and COPD patients. For asthma, we realize that acute exacerbations, leading to hospital readmission, can be related to short-term peak exposure, however, we hypothesized that not only peak exposures but also dust exposure in the preceding months affects the prognosis, possibly due to low grade inflammation caused by ongoing exposure.

Even though the organic components in wood dust (mainly celluloses, hemicelluloses, lignin and low molecular weight organic and inorganic compounds) and farm dust (mainly organic material from plants, fodder, animals, microorganisms, and soil) are probably highly different, quite similar results were seen for the two types of dust.

A strength of this study is the use of comprehensive Danish employment and health registers combined with quantitative estimates of wood and farming dust exposure in a register-based cohort study with minimal risk of recall bias. A limitation is missing smoking information. However, for a subgroup of the cohort from which the wood and farming workers with asthma and COPD of the current study are identified, we observed no association between wood or farming dust and smoking (4). Therefore, we do not anticipate smoking to confound our findings. The observed null finding regarding COPD readmissions is likely explained by the healthy worker survivor effect, which was evident also in our recent publication on wood or farming dust exposure and risk of COPD (4). We assume severity of COPD has a large impact on work ability and that this may underestimate the effect of dust exposure, further supporting the healthy worker survivor effect.

Another limitation is that job task information cannot be accounted for in IEM. However, the farming and wood industry are well-defined entities where the probability of exposure is high and substantial variability in exposure within different farming and wood industries are well documented.

In conclusion, this study indicates that previous year exposure to wood or farming dust increases the risk of hospital readmission for individuals with asthma but not for individuals with COPD. In future studies more detailed information on severity of asthma and COPD are warranted.

\section{Acknowledgements}

We thank the Danish Working Environment Research Fund for funding the study (grant number: 29-201109/200110081344 and grant number 43-201403/20140016763). The authors declare no conflicts of interests

\section{References}

1. GBD 2015 Chronic Respiratory Disease Collaborators. Global, regional, and national deaths, prevalence, disabilityadjusted life years, and years lived with disability for chronic obstructive pulmonary disease and asthma, 1990-2015: a systematic analysis for the Global Burden of Disease Study 2015. Lancet Respir Med 2017 Sep;5(9):691-706. https://doi. org/10.1016/S2213-2600(17)30293-X.

2. Eduard W, Douwes J, Omenaas E, Heederik D. Do farming exposures cause or prevent asthma? Results from a study of adult Norwegian farmers. Thorax 2004 May;59(5):381-6. https://doi.org/10.1136/thx.2004.013326.

3. Sadhra S, Kurmi OP, Sadhra SS, Lam KB, Ayres JG. Occupational COPD and job exposure matrices: a systematic review and meta-analysis. Int J Chron Obstruct Pulmon Dis 2017 Feb;12(12):725-34. https://doi.org/10.2147/COPD. S125980.

4. Vested A, Basinas I, Burdorf A, Elholm G, Heederik DJ, Jacobsen GH et al. A nationwide follow-up study of occupational organic dust exposure and risk of chronic obstructive pulmonary disease (COPD). Occup Environ Med 2019 Feb;76(2):105-13. https://doi.org/10.1136/ oemed-2018-105323.

5. Kauppinen T, Vincent R, Liukkonen T, Grzebyk M, Kauppinen A, Welling I et al. Occupational exposure to inhalable wood dust in the member states of the European Union. Ann Occup Hyg 2006 Aug;50(6):549-61.

6. Basinas I, Sigsgaard T, Heederik D, Takai H, Omland Ø, Andersen NT et al. Exposure to inhalable dust and endotoxin among Danish livestock farmers: results from the SUS cohort study. J Environ Monit 2012 Feb;14(2):604-14. https://doi. org/10.1039/C1EM10576K.

7. Fisher JE, Loft S, Ulrik CS, Raaschou-Nielsen O, Hertel O, Tjonneland A, et al. Physical activity, air pollution, and the risk of asthma and chronic obstructive pulmonary disease. Am J Respir Crit Care Med. 2016 Oct 1;194(7):855-65. https:// doi.org/10.1164/rccm.201510-2036OC.

8. van Dijk CE, Garcia-Aymerich J, Carsin AE, Smit LA, Borlée F, Heederik DJ et al. Risk of exacerbations in COPD and asthma patients living in the neighbourhood of livestock farms: observational study using longitudinal data. Int J Hyg Environ Health 2016 May;219(3):278-87. https://doi.org/10.1016/j. ijheh.2016.01.002. 
9. Le Moual N, Carsin AE, Siroux V, Radon K, Norback D, Torén $\mathrm{K}$ et al. Occupational exposures and uncontrolled adultonset asthma in the European Community Respiratory Health Survey II. Eur Respir J 2014 Feb;43(2):374-86. https://doi. org/10.1183/09031936.00034913.

10. Vandenplas O, Dressel H, Wilken D, Jamart J, Heederik D, Maestrelli P et al. Management of occupational asthma: cessation or reduction of exposure? A systematic review of available evidence. Eur Respir J 2011 Oct;38(4):804-11. https://doi.org/10.1183/09031936.00177510.
11. Paulin LM, Diette GB, Blanc PD, Putcha N, Eisner MD, Kanner RE et al.; SPIROMICS Research Group. Occupational exposures are associated with worse morbidity in patients with chronic obstructive pulmonary disease. Am J Respir Crit Care Med 2015 Mar;191(5):557-65. https://doi.org/10.1164/ rccm.201408-1407OC.

Received for publication: 17 December 2019 